\title{
An inquiry of stock yield between different industries
}

\author{
Zhaoji Tang \\ School of Economics and Commerce, South China University of Technology, Guangzhou 510000, \\ China
}

tangzhaoji19951229@gmail.com

Keywords: Principle Component analysis, stock yield.

\begin{abstract}
There are many essays talking about decisions in choosing stock. Based on former researchers' study, this paper focuses on 4 possible reasons for explaining the stock yield among different industries. With the use of Principle Component analysis, we try to simplify our variables. Then, we choose 26 manufacturing companies in Shanghai Stock Exchange, and make multiple linear regression to figure out the significance of variables. From our result, we find that the most three important principal components can well explain the different stock yield of those 26 companies. Hence, we testified that these four independent variables can explain the difference of stock yield among divergent industries. Furthermore, we provide a different way to research the variation of stock yield.
\end{abstract}

\section{Introduction}

Since Harry Markowitz proposed the Capital Assets Price Model (CAPM), a lot of hypothesis have been propounded to inquire possible factors that can affect stock yield [1]. In 1976, Stephen A. Ross advanced into Arbitrage Pricing Theory (APT), which states that only systematic risk can affect stock yield [2]. Based on the APT, we use a representative company to represent the whole industry's stock yield, since we hypothesize that companies in the same industry share the same systematic risk. Therefore, this paper focus on the different reasons that can influence the difference of stock yield among different industries. And then, try to give advices for investors to make intellectual decisions in choosing stocks. Based on Akira Goto and Kazuyuki Suzuki, Rate of Return on R \& D Investment is very significant for companies' development in Japanese manufacturing industries [3]. Accordingly, the rate of return on investment would also be important for Chinese manufacturing industries. Correspondingly, from view of value investment, rate of return on investment should be an important factors of stock yield. Therefore, we choose this as one of our independent variables. WU Yun-feng and SONG Feng-ming, using the trade data of the A shares in China, examined that stock return's association with liquidity, and found that individual liquidity risk have pregnant influence on stock return [4]. Therefore, we will take individual liquidity risk into consideration, and use the return index of cash flows, which is the most pertinent index, to reflect liquidity risk. According to GA Feltham and JA Ohlson (1995), the correlation of stock and return on common equity is very prominent [5]. It is also be tested by YU Feng-lu in China stock market [6], therefore, return on common equity is also a variable in our research. Finally, according to the financial statements analysis, a company which is good at controlling of the expense, is considered as a profitable one, and would be one that worthy of purchasing. Therefore, Ratio of Profits to Cost is also a variable we consider to have impact on stock yield.

\section{Methodology}

\subsection{The Introduction of PCA}

Principal component analysis (PCA) is a statistical procedure that usually be used to analyze multivariate data. It uses an orthogonal transformation to convert a set of observations of possibly correlated variables into a set of values of linearly uncorrelated variables. The converted variables are called principal components, the number of which is no more than original variables. This 
transformation is defined in such a way that the first principal component has the largest possible variance, and each succeeding component in turn has the highest variance possible under the constraint that it is orthogonal to the preceding components. There are two advantages of PCA. Firstly, it can eliminate the intervention of collinearity, which would be a problem as to making regression analysis. The second benefit is that it can discern important variables. After using the PCA, we will do regression analysis to testify the validity of the methodology.

\subsection{The Basic Steps}

First step: Set the number of sample as $\mathrm{n}$, financial index as $\mathrm{p}$, and we can present the matrix of original data as : $\mathrm{X}=\left(\mathrm{x}_{i j}\right)_{m \times p}(\mathrm{i}=1,2,3, \ldots, \mathrm{n}, \mathrm{j}=1,2,3, \ldots, \mathrm{n})$, in which $\mathrm{x}_{i j}$ indicates the $\mathrm{j}$ financial index of the I company.

Second step: Standardize the data. After the standard process, we can get the new matrix as $\mathrm{Y}=\left(\mathrm{y}_{i j}\right)_{m \times p}$, in which $\mathrm{y}_{i j}=\left(\mathrm{x}_{i j}-\mathrm{x}_{i}\right) / \sqrt{\operatorname{var}\left(\mathrm{x}_{j}\right)},(\mathrm{i}=1,2, \ldots, \mathrm{n}, \mathrm{j}=1,2, \ldots, \mathrm{n}) . \mathrm{X}_{j}$ is the mean value of the $\mathrm{j}$ financial index, and $\sqrt{\operatorname{var}\left(\mathrm{x}_{j}\right)}$ is the variance of the $\mathrm{j}$ financial index.

Third step: Count the correlation matrix R. In which, $\mathrm{R}_{i j}(\mathrm{I}, \mathrm{j}=1,2, \ldots, \mathrm{p})$ is the correlation between the previous variables $Y_{i}$ and $Y_{j}$, the formula is presented below:

$$
\mathrm{R}_{i j}=\frac{\sum_{k=1}^{n}\left(\mathrm{Y}_{k j}-\mathrm{Y}_{i}\right)\left(\mathrm{Y}_{k j}-\mathrm{Y}_{j}\right)}{\sqrt{\sum_{k=1}^{n}\left(\mathrm{Y}_{k j}-\mathrm{Y}_{i}\right)^{2}\left(\mathrm{Y}_{k j}-\mathrm{Y}_{j}\right)^{2}}}
$$

Fourth step: Computer the eigenvalue and eigenvector. Solve the equation that $|\lambda \mathrm{E}-\mathrm{R}|=0$, then count the eigenvalue $\lambda_{i}(\mathrm{I}=1,2, \mathrm{p})$. Because $\mathrm{R}$ is a positive definite matrix in which all of $\lambda_{i}$ are positive, order them with its magnitude, which is $\lambda_{1} \geq \lambda_{2} \geq \cdots \geq \lambda_{p} \geq 0$. The eigenvalue is the variance of each principal component, its magnitude reflects the function of each principal component in describing objects. According to the equation $|R-\lambda| U=0$, we can ascertain the matrix $U$ of eigenvectors.

Fifth step: Calculate the principal factor loadings and explain principal components. The factor loading is the correlation coefficient of component $Z_{i}$ and the original data $X_{i}$, which is represented as $R\left(Z_{i} X_{i}\right)$. The factor loading reveals the correlation between principal component and financial indexes, and explain the economic meaning of principal components. Then we will give each principal components new explanation according to the result of the computer. The principle components are the linear combination, in which the coefficients of each variable is different, of financial indexes. Generally, the bigger absolute value coefficient indicates the bigger contribution of the financial index to the principal component. We will regard the principal component as a synthesis of several financial indexes.

Seventh step, we would construct the function of stock yield by the principal factors.

$\mathrm{P}=W_{1} Z_{1}+W_{2} Z_{2}+\ldots+W_{M} Z_{M}$

In this equation, $\mathrm{P}$ represents the stock yield, and $W_{1}, \ldots, W_{M}$ indicates the contribution of principal components. We will computer the outcome in descending order [7].

Eighth step, using the most important principal components, which could explain over $95 \%$ of the change of independent variable, to do regression analysis with stock yield, testify the model and get corresponding analysis.

\subsection{Sample and Variables Selection.}

Based on the introduction of this paper, we select the data of 26 manufacturing companies in Shanghai Stock Exchange. All of these companies are typical corporations in different industries so we choose their stock yield as the dependent variable to represent the yield of different industries. We use the rate of return on investment, Ratio of Profits to Cost, the return index of cash flows and the return on common equity as the independent variables which are correlated with dependent variable. 
Table 1. Statistic Summary

\begin{tabular}{cccc} 
Variable & Mean & Median & Variance \\
\hline Stock Yield & 1.822 & 1.415 & 4.485 \\
Rate of return on Investment & 0.227 & 0.155 & 0.077 \\
Ratio of Profits to Cost & 1.232 & 1.025 & 0.436 \\
The Return Index of Cash Flows & 2.738 & 2.225 & 4.141 \\
The Return on Common Equity & 1.101 & 1.020 & 0.049 \\
\hline
\end{tabular}

As we can see, the data of Stock Yield and The Return index of cash flows are very dispersive, while others are very concentrate. The mean and median of Rate of return on investment are very small which means it is non-effective comparing to other variables.

\section{Results}

\subsection{Extraction of Principal Components}

As we mentioned in the methodology, we want to know the reliability of the PCA, therefore, it is vital to testify whether principal components can be used to explain the variation of stock yield. Because not all of principal components are very useful and meaningful in explaining the dependent variable, we extract the most important principal components, which can explain over $95 \%$ of the change. The percent of the explanation of each principal components is in table 2.

Table 2. Percent Principal Component explained

\begin{tabular}{cc}
\hline & percent_explained \\
\hline The first Principal Component & 0.600 \\
The second Principal Component & 0.309 \\
The third Principal Component & 0.059 \\
The fourth Principal Component & 0.033 \\
\hline
\end{tabular}

As we can see, the first three principal components can explain $96 \%$ of the variation of the dependent variable, which meets our requirement. So we extract the first three principal components as independent variables to do the linear regression.

\subsection{Multiple Linear Regression}

The multiple linear regression outcome by Least Squares Estimation is in Table3. Table 3. Regression Result

\begin{tabular}{|c|c|c|c|c|}
\hline & Coefficients & $S E$ & $t$ Stat & $P$-value \\
\hline Intercept & 1.822 & 0.162 & 11.277 & $<0.001$ \\
\hline Variable1 & 1.197 & 0.106 & 11.246 & $<0.001$ \\
\hline Variable 2 & -0.534 & 0.148 & -3.604 & 0.002 \\
\hline Variable3 & 0.651 & 0.340 & 1.913 & 0.069 \\
\hline \multicolumn{5}{|c|}{ Regression Statistics } \\
\hline & \multicolumn{3}{|c|}{0.931} \\
\hline \multicolumn{2}{|c|}{$R$ Square } & & \multicolumn{2}{|c|}{0.866} \\
\hline \multicolumn{2}{|c|}{ Adjusted R Square } & & \multicolumn{2}{|c|}{0.848} \\
\hline \multicolumn{2}{|c|}{$S E$} & & \multicolumn{2}{|c|}{0.824} \\
\hline \multicolumn{2}{|c|}{ Observed Value } & & \multicolumn{2}{|c|}{26} \\
\hline
\end{tabular}

In this table, Variable1 represents the most important principal component while Variable2 and Variable 3 are the second and the third important components separately. As we can see, the t-stat of Variable1 is so huge that we cannot refuse that the most important component have influence on stock yield. And P-value of Variable2 is also small enough, we also think that it has impact on stock yield. In our regression, the Significance F is less than 0.001, from which we could claim that these variables are jointly significant. From the table of Regression Statistics, we could notice that the value of $\mathrm{R}$ Square is 0.867 , which means that these three variables could explain $86 \%$ of the variance of the stock yield. Therefore, we can conclude that the Rate of return on Investment, ratio of profits to cost, the return index of cash flows and the return on common equity are the most important factors that affect the stock yield of different industries. 


\section{Conclusion}

This essay researched whether Rate of return on Investment, Ratio of Profits to Cost, The Return Index of Cash Flows, and The Return on Common Equity can explain the variation of stock yield. As the revelation of our result, we concluded that these three factors, which are derived from the original four independent factors, can explain the majority change of stock yield of 26 companies we chose. This indicates that the value of companies and the liquidity are very important for stock yield, which would benefit people investors to buy stocks. Moreover, we also show that factors accounting for difference of stock yield in different industries. Additionally, according to the research of FengJu-Xu, we also find the usability of PCA which could help people in further study [7]. However, since PCA is usually used for dimensionality reduction and we just used 4 independent variables, it is not necessary to use this kind of method. Therefore, if we want to well explain all of the differences, we need to add more independent variables. For further study, we will try to find more variables that can explain the difference among divergent industries.

\section{References}

[1]. Markowitz H. Portfolio selection [J]. The journal of finance, 1952, 7(1): 77-91.

[2]. Ross S A. The arbitrage theory of capital asset pricing [J]. Journal of economic theory, 1976, 13(3): 341-360.

[3]. Akira Goto and Kazuyuki Suzuki, The Review of Economics and Statistics, Vol. 71, No. 4 (Nov., 1989), pp. 555-564 R \& D Capital, Rate of Return on R \& D Investment and Spillover of R \& D in Japanese Manufacturing Industries.

[4]. WU Yun-feng\& SONG Feng-ming. Liquidity Risk and Stock Return [J]. Operations Research and Management Science, 2007, 16(2):117-122.

[5]. Feltham G A, Ohlson J A. Valuation and Clean Surplus Accounting for Operating and Financial Activities [J]. Contemporary Accounting Research, 1995, 11(2):689-731.

[6]. YuFeng-Lu. The usefulness of net asset ratio and P/E investment in making decision [D]. Shanghai University of Finance and Economics, 1999.

[7]. FengJu-Xu, Feng-Wang. Financial Risk Assessment Model Based on Principal Component Analysis [J]. Finance and Accounting Monthly, 2008(35):48-50. 